\title{
AC 2010-502: RESTRUCTURING OF AN ELECTRONICS LAB USING COMPREHENSIVE STUDENT FEEDBACK
}

Adrian Ieta, State University of New York, Oswego

Rachid Manseur, SUNY-Oswego

Thomas Doyle, McMaster University 


\section{Restructuring of an Electronics Lab Using Comprehensive Student Feedback}

SUNY Oswego is engaged in introducing two new engineering programs. Last year, a software engineering program was approved and a new Electrical and Computer Engineering program, supported by the Computer Science and Physics departments, is progressing in its development. As a transition effort, two tracks were thought of: an electrical engineering track in Physics and a computer engineering track in Computer Science. In an effort to establish the electrical engineering track in Physics, some of the physics courses are revised. The present paper describes the restructuring of an Electronics lab course currently taught mainly to Physics majors. As part of the modification, the previous labs were initially revised and the new developments were tested on last year's students. The course has to meet engineering accreditation requirements while serving the needs of Physics and Computer Science majors. Accordingly, the old versions of the labs were standardized to unitary presentation, new labs were introduced, and student feedback on the relevance of topics, quality, and further development needs was recorded on a regular basis. The lab content was integrated with the Electronics course that it essentially serves. The lab experience and the collected feedback are being used for writing a laboratory manual and further fine tuning will be performed with the help of the incoming students enrolled in the course. The experience with restructuring the course and blending in the students' needs has been very positive and the lessons learned from this initiative may prove useful to other instructors in their own approach to modifying electrical engineering labs.

\section{Introduction}

Engineering education is an important factor for sustained economic growth and progress through technological innovation. The analysis of global development suggests that the next economic revolution will occur around a knowledge-based economy, whose intellectual capital will be the measure of its ability to compete in the global marketplace. Given the above issues, the curriculum in general and the engineering curriculum in particular must be examined from a new and dynamic perspective ${ }^{1}$. To meet increasing demands for engineering professionals, several higher education institutions that traditionally offered degree programs in the liberal arts have started or are planning to offer engineering degree programs $^{2}$.

The university enrolls about 8200 students in over 100 programs of study in the Arts, humanities, sciences, and business. A Software Engineering degree has recently received state approval and a program in Electrical and Computer Engineering (ECE) is under development (the proposal is in the approval phase at university level). A new science and engineering building is in the last phase of planning; it will house natural sciences, mathematics, computer science, and engineering. The ECE program is conceived to be competitive within the engineering education field and to respond to the expected needs of the engineering profession. An ECE track has been established in the CS department. A similar ECE track is planned for implementation in the Physics department in order to help with the successful creation of the new ECE department Another improvement is the revision and modernization of the mathematics content in the curriculum ${ }^{3}$. The envisioned ECE program will rely on proven innovative teaching methods based on a project-based, hands-on, active-learning approach to engineering education. The main teaching method to be adopted is studio-based ${ }^{4,5}$, which combines hands-on experimenting with lecturing, as opposed to the traditional lectures and lab sessions. The use of projects

in the curriculum motivates student learning and facilitates understanding of class material ${ }^{6}$. The developed curriculum allows students to graduate as engineers after taking a total of 126 semester credit hours distributed into core courses, cognate courses, electives, and general education requirements. The 
facilities planned for ECE consist of several studio and project labs and the curriculum is developed with the intent of incorporating multidisciplinary courses with a modern approach to teaching communication, basic science, and mathematics skills. As students can now own portable versions of a laboratory station in the form of computer attachments small enough to carry in their backpacks ${ }^{7}$ the choice of the lab equipment was the use of traditional laboratory stations with stand-alone instruments along with sets of computer-based measurement equipment ${ }^{8}$. One of the ECE faculty is currently based in the Physics department teaching courses related to electrical engineering. The inherited Electronics course and lab were in need of significant restructuring. The goal of this paper is to present the effort underway in restructuring the lab course for further inclusion in the ECE program, and this experience is thought to be useful for others as well.

\section{The laboratory course restructuring plan}

The Electronics course ( 3 credit hours) is currently taught in the Physics department in the classical fashion of a separate theory course and a lab course ( 1 credit, two-hour labs). The course mainly enrolls Physics students and is usually of small class size ( 8 students at the time it was taught by us). In the past, students had issues related to lab experiments decoupled from the studied theoretical concepts, as well as to the level of difficulty of concepts presented in lectures. Old lab equipment as well as minimum help from the lab assistant, not particularly trained in electronics, along with the lack of a lab manual available to students were additional factors that made teaching this course more difficult. Laboratories were in mixed non-unitary hand-written / typed format, combining introductory and advanced experiments, not necessarily in a progressive way. As this course was taught by the new faculty with the idea of later integrating it in the ECE department as cross-listed for Physics students, the need for a restructuring process became apparent.

The following steps were considered:

1. Change lab experiments to match lecture content and available equipment

2. Synchronize lecture concepts and lab topics

3. Select and design new lab experiments

4. Continuously collect student feedback on each performed lab

5. Generate a digital version of the labs in a unitary format (the same format for all labs, professional drawings and schematics)

6. Implement changes to the lab content as indicated by student feedback (including addition of new labs)

7. Test the lab changes on the new student pool next time the course is taught

8. Collect comprehensive student feedback on the labs

9. Publish the lab manual if the feedback was satisfactory 
10. Periodically update and upgrade the lab manual according to available equipment and developments in the field

11. Integration of lab and lecture in a studio format

Due to the fact that the Electronics course was rather advanced and the enrolled Physics students did not have an Electrical Circuits preparation to start with, a careful selection of the textbook was required. The content of the course was broad and covered both Circuits and Electronics topics within one semester. The course required a mixture of lectures, problem solving sessions, Power Point presentations for more complicated circuits, and Multisim simulation software for lecture delivery.

Figure 1 illustrates the procedure that has been used in order to define student needs and reorganize the laboratory to blend with the lecture content. The restructuring plan of the Electronics Lab course is viewed in a dynamic perspective. Currently the Lab serves the needs of Physics students, while in the near future it will mainly serve the needs of the future ECE students (possibly including some students who have currently taken the course). Therefore, the need for Lab restructuring at this time is paralleled by the need to tune in the content to present and future student needs (an adapted course will be in the future part of the ECE program). An integration of laboratory and lecture will be performed in the future, as the entire ECE program and laboratory designs (building facilities) were conceived in this way.

In the current phase, lab experiments were tested in lab conditions and modified in order to match the lecture curriculum and relevant engineering content. As there was no electronic format for the laboratories taught for this course, the lab descriptions and drawings have been redone in a unitary manner (professional software was used for schematics and drawings, as opposed to the initial use of hand-drawings) and matched to the progression of the Electronics lectures (see Annex), which required a significant amount of time. However, the order and content of the labs were slightly modified from the initial planning as shown in Table 1.

\section{Student feedback}

Student feedback was collected on each and every lab. The work done during the term along with student feedback will allow us to improve the latest version of the laboratories and prepare a printed laboratory version in the future, with obvious educational advantages for students. For now, the prepared lab content was uploaded via the Angel system in electronic format to be accessible to students. Valuable feedback and suggestions were also gathered from the previous instructor who taught the course and from the Physics lab assistant. The work in the lab was conducted either individually (introductory labs) or in pairs (more advanced labs) allowing for significant development of lab skills.

An initial survey regarding the topics of interest to students revealed the following:

Question: "What topics are you mostly interested in?"

Answers: "How devices work; Realistic applications in Physics; How electricity makes things work; Amplifiers and related topics; Applications of the material in everyday life; circuits; Not sure; Loops, diodes, capacitors and inductors; Applications of electrical engineering; Diodes and amplifiers; I would like to know all of them by the end of the semester." 


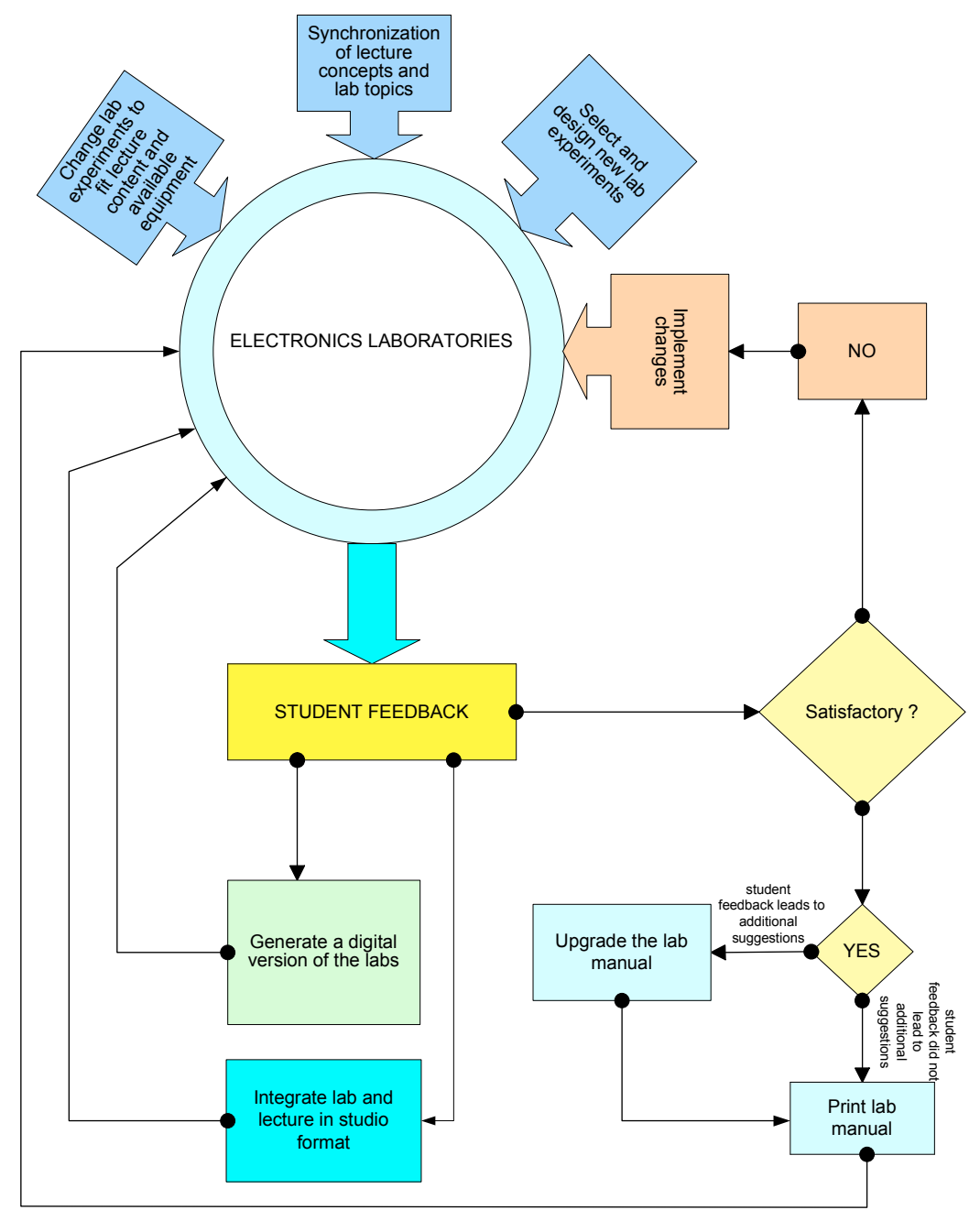

Figure 1 Flowchart for restructuring the Electronics lab course.

\begin{tabular}{|l|l|}
\hline L1 & Ohm's law; resistors \\
\hline L2 & Simulation Circuits: Superposition, Thevenin, Power transfer \\
\hline L3 & Introduction to oscilloscope measurements 1 \\
\hline L4 & \multicolumn{1}{|c|}{ Introduction to oscilloscope measurements 2 } \\
\hline L5 & Diode characteristics \\
\hline L6 & Transistor characteristics \\
\hline L7 & Transistor Amplifier \\
\hline L8 & Transistor-Transistor-Logic /TTL gates \\
\hline L9 & Flip-Flops \\
\hline L10 & RC circuits \\
\hline L11 & RLC Circuit/ Resonance \\
\hline L12 & Operational Amplifiers - Differentiation /Integration \\
\hline
\end{tabular}

Table 1. Laboratory Experiments 
It can be noticed that students do not appear to have much initial background in electronics at the time they enrolled. This remark had to be factored in the teaching methodology, both for the course and the lab.

Based on one of our previous studies ${ }^{9}$ the questionnaire of Table 2 was proposed to students during lecture time around mid-term.

"On a scale from 1 to 5 (5 is the highest value) how do you perceive the course so far?"

\begin{tabular}{|l|}
\hline Question \\
\hline Course content is interesting \\
\hline The course is challenging \\
\hline I learn new things in the course \\
\hline The course appears to be taught well \\
\hline Support from the instructor is appropriate \\
\hline Homework is conducive to meaningful learning \\
\hline There is too much homework \\
\hline Textbook is good \\
\hline Uploaded material is helpful \\
\hline Grading is fair \\
\hline
\end{tabular}

Table 2. Lecture questionnaire.

The results of the survey are presented in Figure 2 (number of responses: 8 out of 8 students ). It is apparent from Figure 2 that the material covered in the Electronics course is fairly new to students as their perception of learning new things is rated at 4.75/5 and also the course challenge average is high 4.5/5. The other results in the chart are also useful for tuning course content to student needs. The textbook rating was rather low, which means that the textbook is likely to be changed in the future. Otherwise, homework seemed appropriate and grading was perceived as fair, which was also reflected in the students' evaluation of teaching.

In addition, students completed a separate questionnaire given in Table 3 for each lab:

"On a scale from 1 to 5 (5 is the highest agreement value) how do you perceive the laboratory work?"

\begin{tabular}{|l|l|}
\hline Question & Lab\# \\
\hline The lab is relevant to course content & \\
\hline Directions for the lab are clear & \\
\hline The lab is interesting & \\
\hline The lab is too long & \\
\hline Post-lab work is too challenging & \\
\hline Support from the instructor is appropriate & \\
\hline Lab work is conducive to meaningful learning & \\
\hline Additional postlab questions/problems are needed? & \\
\hline
\end{tabular}

Table 3. Lab questionnaire. 


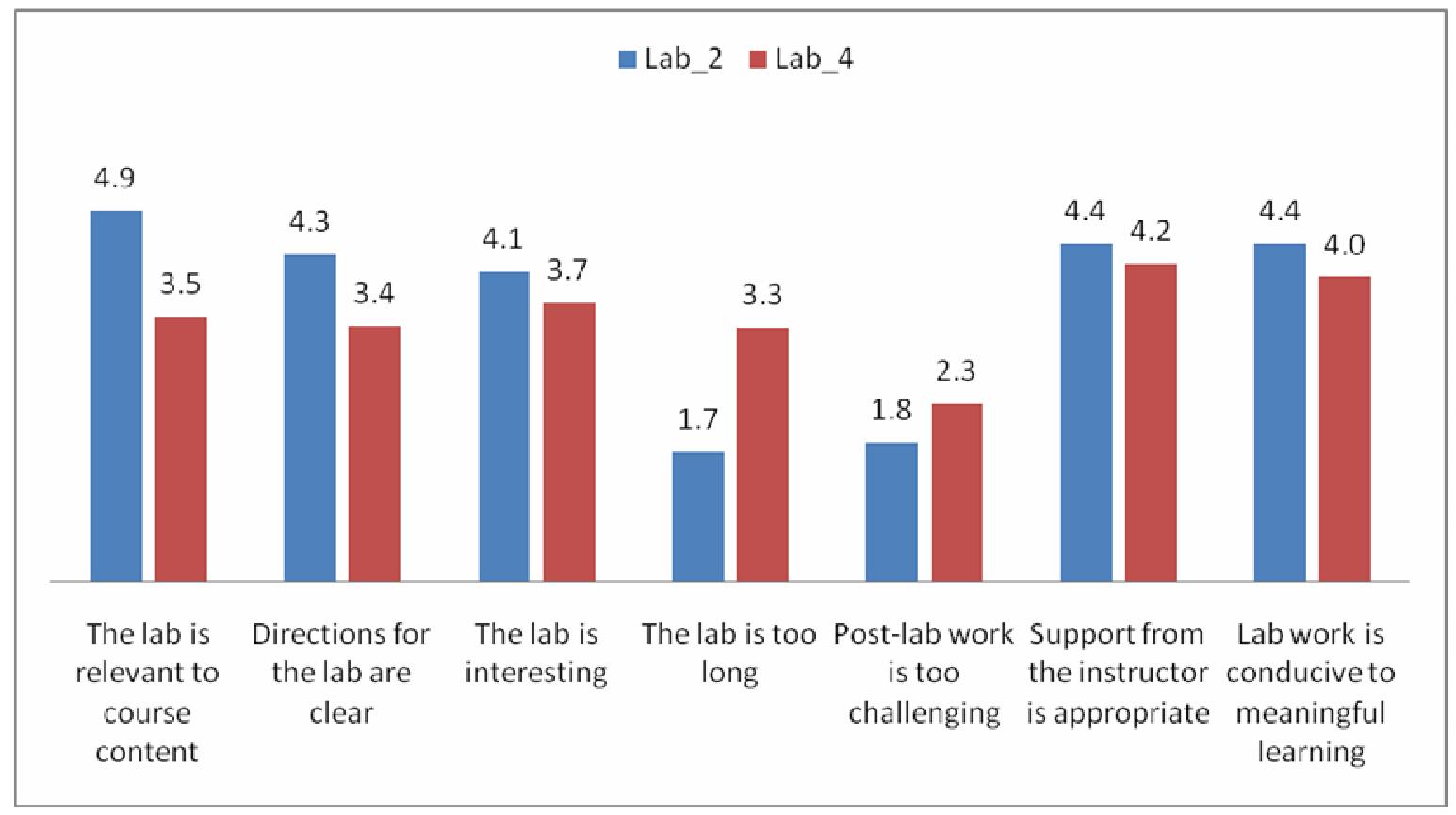

Figure 2 Average student-rating for Lab 2 and Lab 4 (scale 1 to 5 with 5 being maximum)

Sample responses to most of the questions in Table 3 are shown in Fig.2. The feedback shows that students in general appreciated the implemented changes.

Based on student feedback, very specific issues related to each lab were identified and those issues were addressed for the next course. It became possible to rank the laboratories according to student preferences, which will further facilitate the selection of the labs that can be replaced or substantially restructured. The information about the timeframe needed by the students to perform the lab in good conditions was also valuable, as some labs appeared to be short while others were much too long. It was also noticed that students would greatly prefer to work in pairs rather than on their own. Accordingly, after the introductory labs, student pairs were switched. A Circuits Laboratory room was designed to respond to ECE needs in the new Science Building under construction. The same room will also serve the needs of the present Electronics Laboratory course in the future.

An exit survey was also run for the laboratory course.

Question: "What topics did you like most?”

Answers: Basic circuits, superposition, node and loop methods, MOSFETs, Op Amps, TTL gates, BJTs, diodes, Boolean logic, Norton/Thevenin theorems

Question: "To what extent the lab has increased your interest in the course?"

Answers: approx. average: 54\% (26.3 standard deviation)

Question: "To what extent you believe your interest in the course would be boosted by new lab equipment?" 
Answers: approx. average: 27\% (14.7 standard deviation; one answer was 500\% and was excluded from the data set).

It can be noticed from the answers that students definitely refined their topic preferences since the beginning of the course (see the initial survey). It is also apparent that taking the lab course significantly increased interest in the lectures; therefore, the two cannot be treated independently. This conclusion supports our priority in integrating lectures and labs and in synchronizing their content.

The lab was conducted with old equipment, which created some problems on a few occasions. The perspective of new equipment to be used in the lab seems to be agreeable to students, although most of the time it would in fact not make a difference in terms of the concepts studied. This problem will be solved in the near future as the newly designed lab in the ECE department will have brand new and up to date equipment.

Students were asked to rank all the labs on a scale from 0 (the lowest) to 10 (the highest). Figure 3 shows student lab preferences ( 6 out of 8 responses). The ranking clearly points to the successful labs as well as to those in need of refinement (such as Lab 1 and Lab 2 - Table 1).

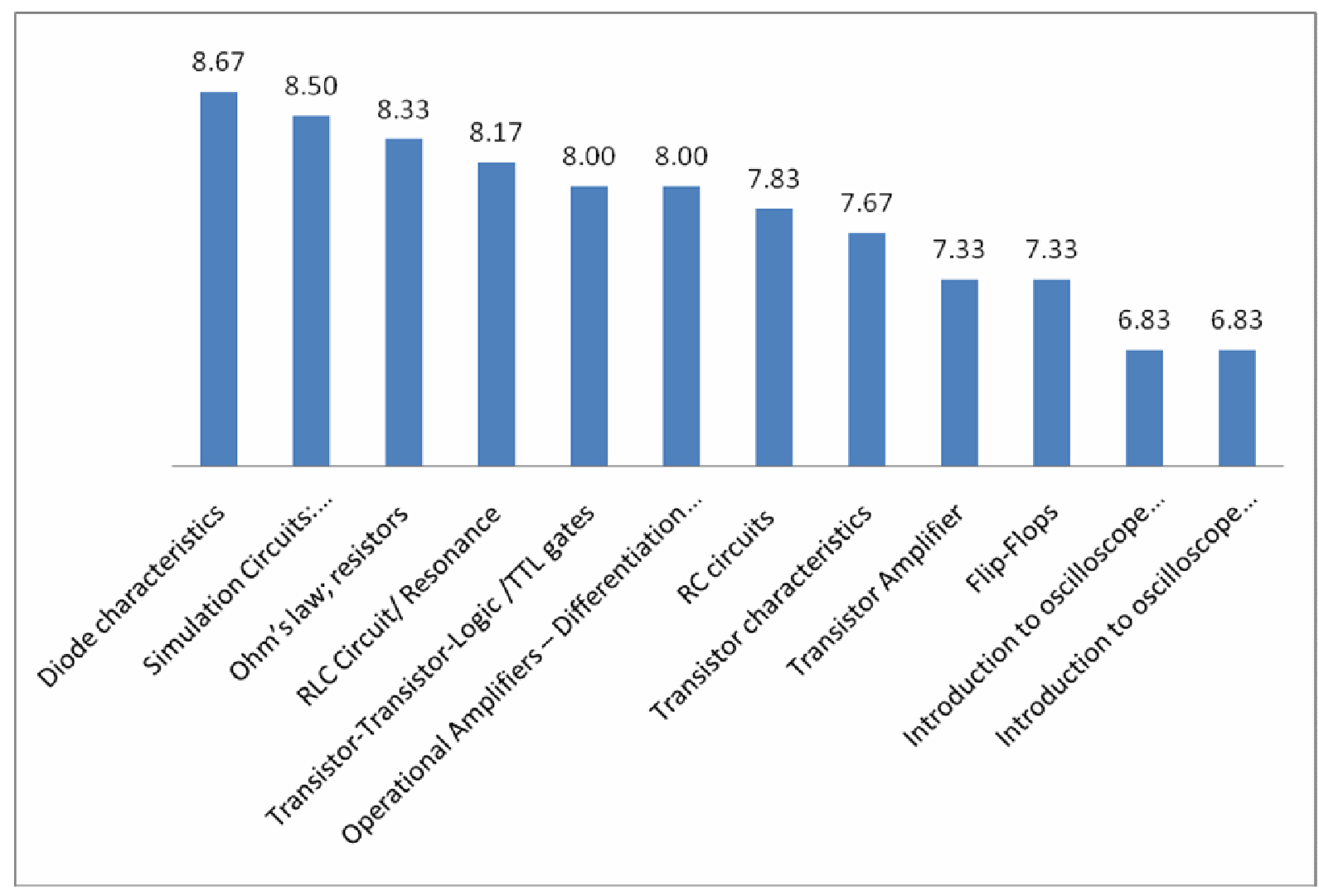

Figure $3 \mathrm{Lab}$ ranking/preferences according to student feedback (10 is the highest and 0 the lowest) 


\section{Conclusions}

A new ECE department is being established. In relation to this process a Physics Electronics laboratory is under restructure. A procedure involving heavy student feedback was presented. Student feedback was used all the time to calibrate course and content to student needs as well as to future ECE needs. The restructuring process started by integrating and synchronizing lecture, lab and content, an approach that appears to be validated by student responses. It was revealed that students perceived lab and course content as linked and their integration and synchronization are beneficial to student learning and interest. The old labs were revised and updated and new labs were developed in electronic format; they are ready to be changed according to student feedback and lecture content. Although experiments could be performed, the infrastructure was poor and students felt that their interest would be significantly increased by new(er) and more reliable equipment. Course changes should be tested on the next Electronics class for further fine tuning and adjustments. The work in the lab was conducted either individually (introductory labs) or in pairs (more advanced labs), allowing for significant development of lab skills. Their progress through experiments was significant. On the other hand, preparing the experiment and lab setups was an intense activity, as the lab assistant provided very little help. In the future this can change as the procedure and experimental setup are better defined. This experience demonstrates that the use of student feedback in identifying the necessary changes was very valuable for the further improvement of the Electronics lab and lecture. The process of lab restructuring will continue and will be naturally extrapolated to other ECE labs to be developed. A prelab section and exercises will be added in the future for a more independent and active involvement of the students before the lab. Other engineering educators may find our approach to lab improvement beneficial.

\section{References}

[1] Tryggvason, G, and D. Apelian. "Re-Engineering Engineering Education for the Challenges of the 21st Century." Journal of the Minerals Metals and Materials Society 58.10 (2006): 14-17.

[2] Morrell, D. et al. "A Flexible Curriculum for a Multi-disciplinary Undergraduate Engineering Degree." Proceedings of the IEEE/ASEE Frontiers in Education Conference, 2005.

[3] Panel Discussion - Manseur, R., Ieta, A., Manseur, R., (October 18 - 21, 2009) "Reforming Mathematics Requirements for a Modern Engineering Education." Frontiers in Education Conference (FIE 2009), San Antonio, Texas.

[4] Vallino, J. R, and R. S Czernikowski. "Thinking Inside the Box: A Multi-Disciplinary Real Time and Embedded Systems Course Sequence." Proceedings of the IEEE/ASEE Frontiers in Education Conference, 2005.

[5] Avery, J.P.; Chang, J.L.; Piket-May, M.J.; Sullivan, J.F.; Carlson, L.E.; Davis, S.C. "The integrated teaching and learning lab." Frontiers in Education Conference, 1998.

[6] Manseur. R.,"Hardware Competitions in Engineering Education." Proceedings of the IEEE/ASEE Frontiers in Education Conference, 2000.

[7] Open Instrumentation Project. Internet Document. http://www.syscompdesign.com/oip.htm.

[8] Manseur, R., Ieta, A., "Integration of an Innovative Engineering Program in a SUNY College." ASEE Annual Conference \& Exposition, Austin, TX, 2009.

[9] Ieta, A., Manseur, R., and Doyle, T. E. (June 14 - 17, 2009) "Effective criteria for teaching and learning." The 2009 ASEE Annual Conference \& Exposition, Austin, TX, 2009. 


\section{ANNEX \\ Integration and Synchronization of lecture and Lab Content \\ Lecture_1. Introduction}

\section{Lab_0. Introduction}

Lecture_2. KVL, KCL resistive network analysis

Lecture_3. Nodal analysis

Lab_1. Ohm's law; resistors

Lecture_4. Linearity, superposition

Lecture_5. Thevenin's equivalences

Lab_2. Equivalent circuits

Lecture_6. Thevenin and Norton equivalences

Lecture_7. Loop method

Lab_3. Introduction to oscilloscope, frequency generator; power supplies; breadboard

Lecture_8. Diodes

Lecture_9. Diode applications; Review1

Lab_4. Diode characteristics

Lecture_10.Exam1

Lecture_11. Bipolar junction transistor(1) BJT (handout)

Lab_5. Transistor characteristics

Lecture_12. Discuss exam1

Lecture_13. Bipolar junction transistor(2) BJT (handout) 


\author{
Lab_6. Transistor Amplifier \\ Lecture_14.Digital abstraction \\ Lecture_15. Boolean logic, combinational gates \\ Lab_7. Transistor-Transistor-Logic/TTL gates \\ Lecture_16. MOS switch, S and SR model, MOS gate design \\ Lecture_17. MOS amplifier \\ Lab_8. Flip-Flops \\ Lecture_18. Capacitors and inductors \\ Lecture_19. Exam2
}

Lab_9. RC circuits (part 2)

Lecture_20. Discuss Exam2

Lecture_21. Transients

Lecture_22. Sinusoidal steady state analysis, freq response; impedance

Lab_10. RC circuit/ AC excitation and RL circuit/ AC excitation

Lecture_23. Filters

Lecture_24. Op-amp abstraction

Lab_11. RLC Circuit/ Resonance

Lecture_25. Op-amp abstraction

Lecture_26. Feedback, stability, oscillators, clocking

Lab_12. Operational Amplifiers - Differentiation /Integration

Lecture_27.Inductance simulation (handout)

Lecture_28. 555 timer (handout)/ Review 